\title{
A Educação Cooperativista na Formação de Catadores de Resíduos Sólidos em Iguatu, Ceará.
}

\section{The Cooperative Education Collectors Training Solid Waste in Iguatu, Ceará.}

\author{
Anny Kariny Feitosa*ı, Gil Heânya Parente Landim², Kevin Brasil da Silva ${ }^{3}$, Gean Duarte da Silva ${ }^{4}$
}

\begin{abstract}
Resumo: A presente pesquisa teve por objetivo conhecer a percepção dos catadores de resíduos sólidos atuantes no município de Iguatu, CE, sobre a realidade de trabalho e contribuição da educação cooperativista na formação profissional. Para a coleta dos dados foi utilizada a técnica de entrevista de grupo focal, com a participação de 10 (dez) catadores de resíduos sólidos que atuam no lixão do referido município, em que foi possível a interação dos participantes, discussão e manifestação de suas opiniões. A análise de dados se deu sob a temática de Bardin (2011), por meio da análise de discurso de conteúdo. Como resultado, foi possível constatar a importância da educação cooperativista como um processo permanente de base na formação e capacitação profissional dos catadores de recicláveis. Além disso, observou-se a necessidade do fortalecimento da organização dos catadores, via a formação de uma cooperativa, possibilitando avanço, por meio de melhores condições de trabalho, vida, renda, valorização do produto e mercado, uma vez que o constante medo de o lixão ser extinto, incentiva a procura dos catadores de materiais recicláveis a buscar a transição da informalidade do trabalho autônomo para a economia solidaria, como uma alternativa viável.
\end{abstract}

Palavras-chaves: Cooperativismo. Educação Cooperativista. Catadores. Lixão.

\begin{abstract}
This research aimed to know the perception of solid waste collectors operating in the city of Iguatu, CE, about the reality of work and contribution of cooperative education in vocational training. To collect the data we used the focus group interview technique, with the participation of ten (10) solid waste pickers working at the dump of the municipality, where it was possible the interaction of the participants, discussion and expression of their opinions. The data analysis was done under the theme of Bardin (2011), through the analysis of speech content. As a result, there has been the importance of cooperative education as an ongoing process based on education and professional training of waste pickers. In addition, there was the need to strengthen the organization of collectors, via the formation of a cooperative, allowing advancement through better working conditions, life, income, product enhancement and market, since the constant fear the dump be extinct, encourages demand for recyclable material collectors to seek the transition from informality of self-employment for the solidarity economy as a viable alternative.
\end{abstract}

Key words: Cooperativism. Cooperative education. Pickers. Dump.

\footnotetext{
*Autor para correspondência

Recebido para publicação em 20/08/2015; aprovado em20 /09/2015

${ }^{1}$ Mestre em Economia, Instituto Federal do Ceará - IFCE, akfeitosa@hotmail.com

${ }^{2}$ Especialista em Contabilidade Gerencial e Tributária, Instituto Federal do Ceará - IFCE, gilheanya@ yahoo.com.br

${ }^{3}$ Graduando em Tecnologia em Irrigação e Drenagem, Instituto Federal do Ceará - IFCE, kevinbrasil_tid@yahoo.com.br

${ }^{4}$ Graduando em Tecnologia em Irrigação e Drenagem, Instituto Federal do Ceará - IFCE, gean_tid@yahoo.com.br
} 


\section{INTRODUÇÃO}

Quando se fala em cooperação observa-se que a sua história está diretamente ligada ao desenvolvimento humano, ou seja, à história da humanidade. Entende-se que o desenvolvimento humano é o processo pelo qual cada indivíduo se forma como ser biológico, psicológico, sociológico, cultural e espiritual, desde o momento da concepção até a morte. Ocorrendo de forma interativa constante entre o indivíduo, sua estrutura biológica e mental, e o meio em que se encontra inserido.

Ao falar no desenvolvimento humano, sabe-se que nele também está inserido o processo de formação da consciência e é a partir do alargamento desta que o indivíduo se reconhece como cidadão, parte de uma política social, econômica, cultural, religiosa e educacional entre outros.

Paulo Freire (2002, p.56) afirma que "na medida em que os seres humanos atuam sobre a realidade, transformando-a com seu trabalho, que se realiza de acordo como esteja organizada a produção nesta ou naquela sociedade, sua consciência é condicionada e expressa esse condicionamento através de diferentes níveis".

Assim, o indivíduo encontra recursos, através da perspectiva educacional, consolidando as bases de sua subjetividade e permitindo desenvolver suas potencialidades.

Segundo Félix Guattari (2001, p.46) "as sociedades capitalísticas fabricam hoje em dia, para colocá-las a seu serviço, três tipos de subjetividade: uma subjetividade serial correspondendo às classes salariais, uma outra à imensa massa dos "não-garantidos" e, enfim, uma subjetividade elitista correspondendo às camadas dirigentes".

Diante de tal reflexão, é possível entender o porquê da dificuldade do acesso à educação às classes menos favorecidas: para manter um indivíduo no servilismo, sonegando-lhe o acesso à educação.

"Mais uma prova de que a educação libertadora, problematizadora, já não pode ser o ato de depositar, ou de narrar, ou de transferir, ou de transmitir "conhecimentos", (FREIRE, 2011, p. 39). Ela precisa permitir ao indivíduo vislumbrar horizontes mais distantes da realidade que lhe fora imposta.

Desta maneira, torna-se evidente que a educação propicia a humanização e juntas, educação e humanização, permitem a formação de um indivíduo consciente dos seus atos em relação a si mesmo, ao próximo, enfim à sociedade na qual está inserido.

De acordo com Brandão (1995, p. 26), a educação é "um meio de produção de poder da sociedade civil e, através dele, um caminho de conquista de participação ativa e consciente dos rumos da sociedade". Para Assmann (2003, p. 26) "a educação terá um papel determinante na criação da sensibilidade social necessária para reorientar a humanidade".

Libâneo (2005, p. 22) define a educação como "o conjunto das ações, processos, influências, estruturas, que intervêm no desenvolvimento humano de indivíduos e grupos na sua relação ativa com o meio natural e social, num determinado contexto de relações entre grupos e classes sociais".

Segundo Marques (1996, p. 14), “a educação se cumpre num diálogo de saberes, não em simples troca de informações, nem em mero assentimento acrítico a proposições alheias, mas na busca do entendimento compartilhado entre todos os que participam da mesma comunidade de vida, de trabalho, de uma comunidade discursiva de argumentação".

Diante do processo de convivência social, de sua sobrevivência e afirmação, na sua relação com a natureza e com os demais seres humanos, o indivíduo constrói o conhecimento, processa a educação, aprende e desenvolve suas capacidades.

Neste sentido, o movimento cooperativista relaciona a educação como princípio histórico fundamental do processo de organização e funcionamento de uma cooperativa, desde a experiência cooperativa Rochdale, iniciada em 1844, na Inglaterra, segundo Schneider (1999).

Assim, pode-se relacionar as práticas cooperativas e a educação, em que o associativismo e o cooperativismo são construtores de enlaces sociais, "não apenas por razões de competitividade econômica, mas também sob a pressão de uma verdadeira urgência social" (LÉVY, 2007, p. 42-43).

Acredita-se que uma das raízes da educação para a cooperação deve estar pautada na reflexão da emancipação, da valorização humana, da participação, da responsabilidade social, bem como da produção da qualidade de vida. Assim, a educação para a cooperação deve estar mais vinculada e condicionada a um projeto cooperativo concreto, principalmente no que se refere à capacitação técnica e à formação política.

Com o advento da aprovação da lei 12.305, de 02 de agosto de 2010, que institui a Política Nacional de Resíduos Sólidos - PNRS e estabelece diretrizes relativas à gestão integrada e ao gerenciamento de resíduos, promove-se a inclusão e integração dos catadores de materiais reutilizáveis e recicláveis com gestão compartilhada entre poder público e sociedade civil (BRASIL, 2010).

Neste sentido, a PNRS tem como destaque a inserção do conceito de responsabilidade compartilhada, o incentivo ao desenvolvimento de cooperativas ou de outras formas de associação de catadores como forma de uma ação socioambiental.

Entretanto, a criação e a plena efetivação da responsabilidade compartilhada pelo ciclo de vida dos produtos, de forma individualizada e encadeada, envolvendo fabricantes, importadores, distribuidores, comerciante, poder Público e consumidores nas várias cadeias de produção e consumo, são um grande desafio para a implementação da PNRS. Outro ponto importante da PNRS é a inserção da participação efetiva dos catadores nas ações de responsabilidade compartilhada, conforme um dos objetivos da PNRS descritos no Art. $7^{\circ}$, inciso XII da Lei 12.305/2010.

Parafraseando Gonçalves (2005), a partir do ano 2002, a ocupação de catador de material reciclável foi incluída na Classificação Brasileira de Ocupações - CBO, sendo atribuições deste profissional: catar, selecionar e vender materiais, como papel, papelão e vidro, bem como, materiais ferrosos e não-ferrosos e outros materiais reaproveitáveis. Contudo, o ainda é considerado inútil para grande parcela da sociedade, bem como aqueles que trabalham com o lixo são associados a sua matéria prima e recebem, também, os seus estigmas.

Não obstante esta realidade social, os principais mecanismos de operacionalidade da PNRS priorizam a participação e a atuação estratégica e incisiva dos catadores 
de resíduos e suas cooperativas. Inegavelmente, a PNRS e sua regulamentação trouxeram grandes desafios aos catadores de materiais reciclados, que precisarão mudar os modelos atualmente adotados para o êxito de sua implementação, por não estarem, em sua maioria, organizados para assumir tal incumbência. Inclusive, por falta de conhecimento da existência da legislação e de outras políticas públicas de gestão de resíduos sólidos.

São diversos os desafios enfrentados pelos catadores de materiais reciclados no modelo de gestão de resíduos sólidos, definido pela Lei Federal 12.305/2010 e que veio a ser regulamentado pelo Decreto Federal 7404/2010, consolidando papéis extremamente importantes para as cooperativas de reciclagem, onde seu envolvimento e comprometimento poderão determinar o êxito da implementação da PNRS.

Deste modo, a educação cooperativista desempenha um papel importante vista como estratégia de desenvolvimento de recursos humanos, bem como, instrumento de educação. Motivo este que justifica a realização e execução do presente projeto, pois será de grande relevância para a formação pessoal e intelectual de cada cidadão envolvido.

Com base no tema abordado, formula-se a questão norteadora para o presente estudo: na percepção dos catadores, qual sua realidade de trabalho e qual a contribuição da educação cooperativista no seu cotidiano?

Diante deste cenário, a presente pesquisa teve por objetivo conhecer a percepção dos catadores de resíduos sólidos atuantes no município de Iguatu, $\mathrm{CE}$, sobre a realidade de trabalho e contribuição da educação cooperativista na formação profissional. Pretende-se, desta forma, fomentar a discussão sobre o processo de ensinoaprendizagem na educação cooperativista e na prática profissional destes sujeitos.

\section{MATERIAL E MÉTODOS}

A pesquisa foi realizada no âmbito do projeto de extensão "Cooperar Reciclando, Reciclar Cooperando: Formação de Catadores de Resíduos Sólidos", que atende a catadores de resíduos sólidos, atuantes no lixão municipal, realizado por alunos e professores de uma instituição federal de ensino.

Com enfoque qualitativo, o estudo foi elaborado utilizando-se, inicialmente, de pesquisa bibliográfica sobre o objeto de estudo, através de coleta de dados em livros, revistas especializadas e artigos científicos disponíveis na Internet. Além disso, constou de um estudo de caso, que, conforme Gil (2007), consiste em um estudo profundo que permite um amplo e detalhado conhecimento do objeto estudado.

Para a coleta dos dados, foi utilizada a técnica de entrevista de grupo focal, realizado no dia 25 de junho do corrente ano, com a participação de 10 catadores atuantes no lixão de Iguatu, CE, sendo 2 homens e 8 mulheres. As falas dos participantes foram gravadas e, posteriormente, transcritas e analisadas sob a temática de Bardin (2011), por meio da análise de discurso de conteúdo.

A identidade dos participantes foi preservada e utilizaram-se apelidos, tais como "garrafa", "vidro", "pneu" e caneta" para distinção das falas elencadas na seção de resultados e discussão.

\section{RESULTADOS E DISCUSSÃO}

As perguntas norteadoras do grupo focal trataram sobre as condições de trabalho do catador, emprego e renda, a importância da formação em educação cooperativista, o lixão e perspectivas futuras.

Quando se consideram as condições de trabalho e vida dos catadores atuantes no Lixão de Iguatu, CE, tem-se uma opinião homogênea entre os sujeitos, que afirmam passar por dificuldades devido às precárias condições da atuação no lixão municipal. Como exemplo, temos a fala do participante "vidro", que comentou: É ruim. Tem muita mosca, fumaça.

A este respeito, a recente publicação "Situação Social das Catadoras e dos Catadores de Material Reciclável e Reutilizável" relata que:

Entre os riscos a que estes trabalhadores são
frequentemente submetidos estão: a exposição
ao calor, a umidade, os ruídos, a chuva, o risco
de quedas, os atropelamentos, os cortes e a
mordedura de animais, o contato com ratos e
moscas, o mau cheiro dos gases e a fumaça
que exalam dos resíduos sólidos acumulados, a
sobrecarga de trabalho e levantamento de peso,
as contaminações por materiais biológicos ou
químicos, etc. (IPEA, 2013, p. 10).

Quando perguntados sobre as possibilidades de emprega e geração de renda, os participantes indagaram a concorrência sofrida pela existência de catadores de rua e garis, que coletam materiais recicláveis com fins de comercialização. Destacam-se as falas do participante "Garrafa": As condições de trabalho tá fraca né. Os 'catador' da rua, que nem os gari dos caminhão, tá catando igualmente a gente. Os catadores também mencionaram que o preço do reciclável oscilava muito, o que tornava instável sua renda mensal. Tal feito pode ser constatado ainda na fala do participante "Garrafa": Principalmente o preço do plástico que tá cada vez diminuindo, que às vezes o 'homi' fala de 'abaxar', uma hora 'baxa', outra hora num 'abaxa'. (Garrafa).

De acordo com o IPEA (2011 apud IPEA, 2013), no trabalho de coleta de recicláveis há "a incidência de uma maior sazonalidade no desempenho das atividades, que ocorre conforme variações nos preços dos materiais recicláveis, na oferta de resíduos [...]". Deste modo, pode ser observado que a variação no preço do produto e a coleta realizada pelos catadores de rua e garis são os principais indicativos da ameaça à renda familiar do catador no final do mês. Salientase que $96 \%$ dos catadores que atuam no lixão de Iguatu percebem mensalmente renda inferior a 1 (um) salário mínimo (FEITOSA, et. al., 2015).

Sobre a possibilidade de trabalhar em outro ambiente ou profissão e a escolha da permanência na função de catador, destacou-se o depoimento do participante "Pneu", que afirmou: "É melhor tá aqui que nas casa dos povo, porque aqui a gente vem no dia que quer, no dia que num quer a gente num vem, nas casa dos outro a gente é obrigado a trabalhar todo santo dia, né. Eu mermo acho bom, um emprego desse aqui.. eи mermo num troco não. Se eu achar um emprego pra mim dar 2 salário, eи num vou não, eи пum saio daqui pra mim ir não, eu num vou mentir". 
Conforme o relato acima, a ausência de uma submissão diretamente a uma figura física, o patrão, configura-se como um dos motivos expostos para a preferência deste trabalho em relação a outro, como os empregos domiciliares que muitas vezes se constituem como única alternativa para esta parcela da população à margem do acesso ao emprego formal (LUCAS, 2015). Destaca-se que o emprego domiciliar citado não se torna um atrativo e chega a ser descartado como alternativa de renda, ainda que de maneira formal e com remuneração superior à obtida no lixão.

Quando questionados sobre a existência do lixão e o seu encerramento, conforme estabelece a legislação vigente, os catadores demonstraram que estão apreensivos com a possibilidade de que não sejam inseridos na atividade de recicladores, temendo por sua fonte de renda e sobrevivência. A este respeito, o participante "Pneu" relatou: "O nosso medo é sair e nois ficar com a cara pra cima. O sonho é ele nunca sair, acredita? Porque se ele sair daqui muita gente vai passar precisão. Porque a maioria do povo da chapadinha vivi daqui de dentro, só quem num vive daqui de dentro é quem é aposentado. Mais quem num é vive socado aqui dentro. Muita gente vai passar fome".

Nestes trechos, o participante "Pneu" se refere ao lixão nunca acabar, pois se sente inseguro de não ter condições de prover o sustendo da família, já que a principal fonte de renda é a catação de materiais recicláveis. Essa necessidade de garantir o sustento da família, muitas vezes, é atrelada à ausência de outra fonte de renda ou da contribuição por parte de um companheiro (a) para ajudar no complemento da renda familiar.

Presos à realidade de trabalho informal que existe há anos na função de catador de matérias recicláveis, pode-se notar que o desejo relatado é continuar na informalidade e garantir a renda familiar. No que se refere a continuar trabalhando na informalidade, Lucas (2015) afirma que a falta de vagas no mercado de trabalho formal contribui para que o trabalho com a coleta de matérias recicláveis no lixão represente uma alternativa. Ainda podemos observar que a ausência da renda, proveniente da catação e a extinção do lixão apavora os trabalhadores, que temem pela insegurança de não ter onde trabalhar, consequentemente, de não terem como prover o sustento da família.

Não obstante, a Política Nacional de Resíduos Sólidos (PNRS) define o fim dos lixões a céu aberto, com o intuito de minimizar os impactos ambientais provenientes do acúmulo de resíduos de maneira inadequada. Contudo, prevê em seu artigo 18 que a prioridade de acesso aos recursos da União para municípios em sua gestão de resíduos, está para a implantação da coleta seletiva mediante a participação de cooperativas ou outras formas de associação de catadores de materiais recicláveis. Observa-se, deste modo, que ao determinar a necessidade de inclusão dos catadores na coleta seletiva, a PNRS proporciona uma nova perspectiva de atuação para esses profissionais em seus municípios (BRASIL, 2010a).

Sobre a Educação Cooperativista e sua importância na formação profissional, os catadores afirmaram que antes da participação no projeto de extensão "Cooperar Reciclando, Reciclar Cooperando: Formação de Catadores de Resíduos Sólidos" não tinham ideia do real significado do cooperativismo, nem mesmo da sua função como catador, conforme afirma o participante "Caneta": "Vou ser sincera com você, eu não tinha ideia do que era realmente cooperativa, só que agora eu já aprendi muito e tô disposta a tá junta e aprender cada vez mais. Eu acho que trabalhar em cooperativa, é você tá ali sempre preparado para trabalhar unido, e no final do dia, sabe aquilo que você fez, e no final das conta ninguém ganhar mais que ninguém".

Corroborando com a afirmação do sujeito "Caneta", Safanelli et al. (2011) afirmam que a cooperativa é uma associação que reúne pessoas e interesses comuns. Nessa associação, todos os participantes têm os mesmos direitos e os mesmos deveres, definidos em seu estatuto.

Salienta-se, contudo, que para que se alcance essa compreensão e participação de todos os envolvidos no processo de transição de trabalho informal como catador para a economia solidária, com base nos princípios do cooperativismo, é necessário um permanente processo de Educação Cooperativista. Neste sentido, a educação é um direito inalienável do quadro social e não um assunto a ser analisado quanto a sua conveniência ou não para a cooperativa.

Sobre a participação no projeto de extensão, que teve como base a Educação Cooperativista, constatou-se que, na percepção dos catadores, a formação possibilitou a interação entre os próprios educandos, além de fomentar entre eles debates e discussões construtivas para sua formação, bem como oportunidade para um novo projeto de vida, por meio da provável criação de uma cooperativa de recicladores no município.

Com isso, ressalta-se que o ensino tem promovido perspectivas de mudanças dos seus hábitos, realidade e melhores condições de trabalho e vida. Destacam-se as falas obtidas a este respeito: "Ah, eu acho que ajudou muito né, porque pelo menos a gente sabe que a gente pode ter outra coisa né" (Caneta); "Nóis não tinha ideia do que era uma cooperativa, e agora nóis sabe" (Vidro). Dessa forma, foi possível constatar, nas falas obtidas durante o grupo focal, a importância que os participantes dão ao processo de ensino voltado para sua realidade, e que a educação cooperativista tem contribuído na formação profissional do catador.

\section{CONSIDERAÇÕES FINAIS}

Constatou-se que, na percepção dos catadores, a formação em educação cooperativista possibilitou a apreensão de conteúdos, a interação entre os próprios educandos, além de fomentar entre eles debates e discussões construtivas. Contudo, este deve ser um processo permanente e contínuo, com vistas à formação e capacitação profissional dos envolvidos.

Verifica-se a necessidade do fortalecimento da organização dos catadores, via a formação de uma cooperativa, possibilitando avanço, por meio de melhores condições de trabalho, vida, renda, valorização do produto e mercado.

\section{REFRÊNCIAS BIBLIOGRÁFICAS}

ASSMANN, H. Reencantar a Educação. Rumo à sociedade aprendente. Petrópolis, RJ: Vozes, 2003.

BRANDÃO, C. R. Em Campo Aberto: escritos sobre a educação e a cultura popular. São Paulo: Cortez, 1995. 
BRASIL. Decreto Federal $\mathbf{n}^{\mathbf{0}}$ 7.405/2010. Institui o Programa Pró-Catador. Brasília: Presidência da República, 2010.

BRASIL. Lei no 12.305, de 2 de agosto de 2010, que institui a Política Nacional de Resíduos Sólidos. Brasília: Presidência da República, 2010a.

DRIMER, Alícia e DRIMER, Bernardo. Las cooperativas escolares. 3 ed. Intercoop: Buenos Aires, 1987.

FEITOSA, A.K.; DAMASCENO, M.M.S.; MARINHO, P.G.; SILVA, K.B. O Perfi dos Catadores frente à Política Nacional de Resíduos Sólidos: O caso do Lixão de Iguatu. Id on Line Revista de Psicologia, Fevereiro de 2015, vol.9, n.25, p. 217-225. ISSN 1981-1189.

FERRINHO. Homero. Educação cooperativa. Lisboa Livraria Popular: Francisco Franco, 1985.

FREIRE, Paulo. Ação cultural para a liberdade. 10 ed., Rio de Janeiro: Paz e Terra. 2002.

FREIRE, Paulo. Pedagogia do oprimido. 50 ed. Rio de Janeiro: Paz e Terra, 2011.

GOHN, M. G. Educação não-formal e cultura política: impactos sobre o associativismo do terceiro setor. São Paulo: Cortez, 2005.

GONÇALVES, R. C. M. A Voz dos Catadores de Lixo em sua Luta Pela Sobrevivência (Dissertação). Mestrado em Políticas Públicas e Sociedade. UECE: Fortaleza, $2005 . \quad$ Disponível em: $<$ http://www.uece.br/politicasuece/index.php/arquivos/d oc_view/52-

ubiacristinamartinsgoncalves 1 ?tmpl=component\&forma $\mathrm{t}=$ raw>. Acesso em: 24 abr 2014.

GUATTARI, Félix. As três ecologias. Campinas. 11 ed. SP: Papirus, 2001.

IPEA. Situação Social das Catadoras e dos Catadores de Material Reciclável e Reutilizável - Brasil. IPEA, 2013.

JACOBI, P. et al. Gestão compartilhada dos resíduos sólidos no Brasil. São Paulo: Annablume, 2006.

LÉVY, P. A Inteligência Coletiva. Por uma antropologia do ciberespaço. Tradução de Luiz Paulo Rouanet. 5. ed. São Paulo: Edições Loyola, 2007.

LIBÂNEO, J. C. Pedagogia e pedagogos, para quê? São Paulo: Cortez, 2005

LOMBARDI, J. C. e GOERGEN, P. (orgs.). Ética e educação: reflexões filosóficas e históricas. Campinas, SP: Autores Associados, 2005.

LUCAS, M.W.A. Nas trilhas da informalidade: a precarização do trabalho dos catadores de materiais recicláveis no lixão de Iguatu-CE. 2015.116p. Monografia (Graduação). IFCE: Iguatu, 2015.
MARQUES, M. O. Educação/interlocução, aprendizagem/reconstrução de saberes. Ijuí: Editora UNIJUI, 1996.

SCHNEIDER, J. O. Democracia, participação e autonomia cooperativa. São Leopoldo, UNISINOS, 1999.

SEVERINO, A. J. Educação e ética no processo de construção da cidadania. Educação e Cidadania, v. 5, p. 29-41, 2006. 